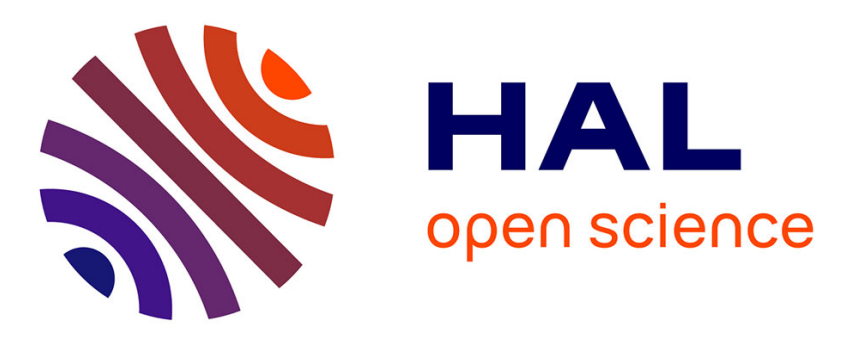

\title{
Dietary n-3 PUFAs affect the blood pressure rise and cardiac impairments in a hyperinsulinemia rat model in vivo
}

Delphine Rousseau, Cécile Héliès-Toussaint, Daniel Moreau, Daniel Raederstorff, Alain Grynberg

\section{To cite this version:}

Delphine Rousseau, Cécile Héliès-Toussaint, Daniel Moreau, Daniel Raederstorff, Alain Grynberg. Dietary n-3 PUFAs affect the blood pressure rise and cardiac impairments in a hyperinsulinemia rat model in vivo. AJP - Heart and Circulatory Physiology, 2003, 285 (3), pp.H1294-H1302. hal02676983

\section{HAL Id: hal-02676983 \\ https: / hal.inrae.fr/hal-02676983}

Submitted on 31 May 2020

HAL is a multi-disciplinary open access archive for the deposit and dissemination of scientific research documents, whether they are published or not. The documents may come from teaching and research institutions in France or abroad, or from public or private research centers.
L'archive ouverte pluridisciplinaire HAL, est destinée au dépôt et à la diffusion de documents scientifiques de niveau recherche, publiés ou non, émanant des établissements d'enseignement et de recherche français ou étrangers, des laboratoires publics ou privés. 
Delphine Rousseau, Cécile Héliès-Toussaint, Daniel Moreau, Daniel Raederstorff and Alain Grynberg

Am J Physiol Heart Circ Physiol 285:1294-1302, 2003. First published Jan 9, 2003;

doi:10.1152/ajpheart.00651.2002

You might find this additional information useful...

This article cites 49 articles, 10 of which you can access free at:

http://ajpheart.physiology.org/cgi/content/full/285/3/H1294\#BIBL

This article has been cited by 8 other HighWire hosted articles, the first 5 are:

Obesity-induced insulin resistance and hepatic steatosis are alleviated by \{omega\}-3 fatty acids: a role for resolvins and protectins

A. Gonzalez-Periz, R. Horrillo, N. Ferre, K. Gronert, B. Dong, E. Moran-Salvador, E. Titos, M.

Martinez-Clemente, M. Lopez-Parra, V. Arroyo and J. Claria

FASEB J, June 1, 2009; 23 (6): 1946-1957.

[Abstract] [Full Text] [PDF]

Long-Chain (n-3) Polyunsaturated Fatty Acids Prevent Metabolic and Vascular Disorders in Fructose-Fed Rats

V. Robbez Masson, A. Lucas, A.-M. Gueugneau, J.-P. Macaire, J.-L. Paul, A. Grynberg and D.

Rousseau

J. Nutr., October 1, 2008; 138 (10): 1915-1922.

[Abstract] [Full Text] [PDF]

Rat heart cannot synthesize docosahexaenoic acid from circulating \{alpha\}-linolenic acid because it lacks elongase-2

M. Igarashi, K. Ma, L. Chang, J. M. Bell and S. I. Rapoport

J. Lipid Res., August 1, 2008; 49 (8): 1735-1745.

[Abstract] [Full Text] [PDF]

Long-term effect of dietary \{alpha\}-linolenic acid or decosahexaenoic acid on incorporation of decosahexaenoic acid in membranes and its influence on rat heart in vivo A. Ayalew-Pervanchon, D. Rousseau, D. Moreau, P. Assayag, P. Weill and A. Grynberg Am J Physiol Heart Circ Physiol, October 1, 2007; 293 (4): H2296-H2304.

[Abstract] [Full Text] [PDF]

\section{Potential impact of carbohydrate and fat intake on pathological left ventricular hypertrophy \\ N. Sharma, I. C. Okere, M. K. Duda, D. J. Chess, K. M. O'Shea and W. C. Stanley \\ Cardiovasc Res, January 15, 2007; 73 (2): 257-268. \\ [Abstract] [Full Text] [PDF]}

Updated information and services including high-resolution figures, can be found at:

http://ajpheart.physiology.org/cgi/content/full/285/3/H1294

Additional material and information about AJP - Heart and Circulatory Physiology can be found at: http://www.the-aps.org/publications/ajpheart

This information is current as of September 7, 2010 .

AJP - Heart and Circulatory Physiology publishes original investigations on the physiology of the heart, blood vessels, and lymphatics, including experimental and theoretical studies of cardiovascular function at all levels of organization ranging from the intact animal to the cellular, subcellular, and molecular levels. It is published 12 times a year (monthly) by the American

Physiological Society, 9650 Rockville Pike, Bethesda MD 20814-3991. Copyright $\odot 2003$ by the American Physiological Society. ISSN: 0363-6135, ESSN: 1522-1539. Visit our website at http://www.the-aps.org/. 


\title{
Dietary n-3 PUFAs affect the blood pressure rise and cardiac impairments in a hyperinsulinemia rat model in vivo
}

\author{
Delphine Rousseau, ${ }^{1}$ Cécile Héliès-Toussaint, ${ }^{1}$ Daniel Moreau, ${ }^{2}$ \\ Daniel Raederstorff, ${ }^{3}$ and Alain Grynberg ${ }^{1}$ \\ ${ }^{1}$ Lipides Membranaires et Fonctions Cardiovasculaires, Institut National de la Recherche \\ Agronomique-UR1154, Faculté de Pharmacie, Université Paris-Sud, 92290 Châtenay-Malabry; \\ ${ }^{2}$ Laboratory of Experimental Cardiovascular Pathophysiology and Pharmacology, Faculté de \\ Médecine, 21033 Dijon, France; and ${ }^{3}$ Department VFHF, F. Hoffmann-La Roche, 4070 Basel, Switzerland
}

Submitted 25 July 2002; accepted in final form 26 December 2002

\begin{abstract}
Rousseau, Delphine, Cécile Héliès-Toussaint, Daniel Moreau, Daniel Raederstorff, and Alain Grynberg. Dietary n-3 PUFAs affect the blood pressure rise and cardiac impairments in a hyperinsulinemia rat model in vivo. $A m \mathrm{~J}$ Physiol Heart Circ Physiol 285: H1294-H1302, 2003. First published January 6, 2003; 10.1152/ajpheart.00651.2002.The cardiovascular consequences of eicosapentaenoic acid (EPA)- and docosahexaenoic acid (DHA)-specific intake were evaluated in vivo in a hyperinsulinemia (HI) model induced by dietary fructose intake. Wistar rats were fed a diet containing (or not for control) either EPA or DHA. The rise in blood pressure (BP), heart rate, and ECG were continuously monitored using an intra-abdominal telemetry system. The myocardial phospholipid fatty acid profile was significantly affected by DHA intake but less by EPA intake. The data indicated a reduced rise in $\mathrm{BP}$ in both DHA and EPA HI groups compared with controls. This result was confirmed by tail-cuff measurement after 5 wk [133.3 \pm 1.67 and $142.5 \pm$ $1.12 \mathrm{mmHg}$ in $\mathrm{n}-3$ polyunsaturated fatty acid (PUFA) and control groups, respectively], whereas n-3 PUFA did not affect $\mathrm{BP}$ in non-HI rats $(116.3 \pm 3.33 \mathrm{mmHg})$. The heart rate was lower in the HI DHA group than in the other two dietary HI groups. Moreover, DHA induced a significantly shorter QT interval. It is concluded that the cardioactive component of fish oils is DHA through a mechanism that may involve the cardiac adrenergic system.
\end{abstract}

hypertension; nutrition; prevention; telemetry; heart

INSULIN RESISTANCE (reduced insulin suppression of hepatic glucose production and reduced insulin stimulation of glucose uptake) is a characteristic feature of Type 2 diabetes [non-insulin-dependent diabetes mellitus (NIDDM)]. The development of NIDDM can be linked to both genetic and environmental factors. Dietinduced insulin resistance is characterized by fasting normoglycemia accompanied by hyperinsulinemia (HI) and impaired insulin suppression of hepatic glucose production $(46,50)$. There is increasing evidence that HI patients also display hypertension (40). Indeed, HI can contribute to a sympathetically mediated rise in

\footnotetext{
Address for reprint requests and other correspondence: A. Grynberg, Institut National de la Recherche Agronomique-UR1154, Lipides Membranaires et Fonctions Cardiovasculaires, Faculté de Pharmacie, Université Paris-Sud, 5 rue Jean Baptiste Clément, 92290 Châtenay-Malabry Cedex, France (E-mail: grynberg@jouy.inra.fr).
}

blood pressure in normal rats (33). A similar phenomenon occurs in a model of psychosocial stress (42). A very strong relationship exists among these risk factors, including hypertension, so that they are now collectively called "syndrome X," which contributes to cardiovascular diseases.

Fish oils are rich in the long-chain n-3 polyunsaturated fatty acids (PUFAs) eicosapentaenoic acid (EPA) and docosahexaenoic acid (DHA). DHA and EPA have antiatherogenic actions, are beneficial in experimental myocardial infarctions, prevent arrhythmias (3, 31), and have a positive effect on mortality in human coronary heart disease (13). Dietary fish oil has also been shown to prevent hypertension (17). In previous studies, our laboratory reported that dietary purified n-3 PUFA can help to prevent the rise of blood pressure in a psychosocial stress model in rats (42) and in the Goldblatt 2K, 1C hypertension model (41). However, it remains to be clarified which one of the n-3 PUFAs (EPA or DHA) is more potent in the prevention of cardiovascular diseases. EPA has been thought to produce its beneficial cardiovascular effects through a stimulation of prostaglandin action (which influences vasodilatation and platelet aggregation), whereas DHA may be cardioprotective via its antiarrhythmic capacity (43). This study was designed to investigate, by continuous clinical evaluation in rats, the separate actions of EPA and DHA in the lowering of blood pressure and the prevention of cardiac dysfunction in a $\mathrm{HI}$ rat model.

\section{METHODS}

The investigation was carried out in agreement with the National Institutes of Health Guidelines for the Care and Use of Laboratory Animals (NIH Pub. No. 85-23, Revised 1996).

Pathophysiological model. Male Wistar rats were obtained from IFFA CREDO (a Charles River company providing laboratory animals; Les Oncins, France) at 8 wk of age and divided into six groups. One-half of the rats, designated the control group, were fed a balanced semipurified gel diet containing cornstarch + sucrose as the carbohydrate sources.

The costs of publication of this article were defrayed in part by the payment of page charges. The article must therefore be hereby marked "advertisement" in accordance with 18 U.S.C. Section 1734 solely to indicate this fact. 
The second half of the animals, designated the HI group, was fed a $62 \%$ fructose diet. Each group was further divided into three subgroups: one group receiving a normal fat diet (NFD group), another group receiving the same fat diet supplemented with EPA (EPA group), and the last group receiving the same fat diet supplemented with DHA (DHA group).

Diets. The rats were fed ad libitum a semipurified gel diet (39) in accordance with the recommendations of the American Institute of Nutrition (1993) and the Nutrient Requirements of Laboratory Animals (1995). The meal was prepared to form a jellied mass, cut into cubes for feeding, stored at $-20^{\circ} \mathrm{C}$, and distributed daily to maintain moisture content. The base fabricated diet was composed of soy protein isolate (140 g/kg, ICN 905456), L-cystine (1.8 g/kg), gelatin (50 g/kg), lipids (80 g/kg), a salt mixture (40 g/kg, ICN 960401), a vitamin mixture (10 g/kg, ICN 960402), choline bitartrate (2 $\mathrm{g} / \mathrm{kg})$, cellulose $(50 \mathrm{~g} / \mathrm{kg})$, and either starch $(526.2 \mathrm{~g} / \mathrm{kg})+$ sucrose $(100 \mathrm{~g} / \mathrm{kg})$ for the control groups or fructose $(626.2$ $\mathrm{g} / \mathrm{kg}$ ) for the HI groups. In the NFD groups, the lipid part (80 $\mathrm{g} / \mathrm{kg}$ ) was composed of $40 \mathrm{~g} / \mathrm{kg}$ cocoa butter (CACAO BARRY) and $40 \mathrm{~g} / \mathrm{kg}$ sunflower seed oil (Fruidor). In the n-3 PUFAsupplemented groups (DHA and EPA groups), the lipid part (80 g/kg) was composed of $40 \mathrm{~g} / \mathrm{kg}$ cocoa butter, $30.4 \mathrm{~g} / \mathrm{kg}$ sunflower seed oil, and $9.6 \mathrm{~g} / \mathrm{kg}$ either DHA or EPA, respectively, supplied as purified ethyl esters (Hoffmann-LaRoche; Basel, France). The fatty acid composition of the diets (Table 1) shows the characteristic trends of the three diets, poor in n-3 PUFAs (NFD diet), rich in EPA (EPA diet), or rich in DHA (DHA diet), with roughly similar contents in saturated fatty acid (SFA; 30\%), monounsaturated fatty acid (MUFA; $30 \%$ ), and PUFA (40\%).

Measurement of blood pressure and ECG. Blood pressure was measured using either the tail-cuff technique or telemetry. The tail-cuff technique was used each week in the three control groups $(n=6)$ and three HI groups $(n=6)$. Each rat was trained to the tail-cuff technique 2 days before each measurement. The measurements were achieved with a Physiograph Desk Model and an Electro-Sphygmomanometer (Roucaire; Paris, France). Five separate measurements were made on conscious rats in a restraining box heated at $40^{\circ} \mathrm{C}$, with the cuff and the pulse-wave transducer set around the tail $\sim 15$ min before measurements.

Table 1. Fatty acid composition as analyzed in lipid blends of the dietary groups

\begin{tabular}{lrrr}
\hline \hline \multicolumn{1}{c}{ Fatty Acid } & NFD & EPA & DHA \\
\hline $14: 0$ & 0.6 & 1.3 & 2.2 \\
$16: 0$ & 15.1 & 12.3 & 12.5 \\
$16: 1 \mathrm{n}-9$ & 0.8 & 1.5 & 2.3 \\
$18: 0$ & 16.0 & 14.3 & 15.4 \\
$18: 1 \mathrm{n}-9$ & 26.4 & 23.3 & 24.2 \\
$18: 2 \mathrm{n}-6$ & 39.2 & 29.7 & 28.0 \\
$20: 5 \mathrm{n}-3$ & $\mathrm{ND}$ & 12.2 & 0.3 \\
$22: 5 \mathrm{n}-3$ & $\mathrm{ND}$ & 0.1 & 1.5 \\
$22: 6 \mathrm{n}-3$ & $\mathrm{ND}$ & 0.2 & 8.2 \\
Minor SFA & 0.6 & 1.4 & 2.2 \\
Minor MUFA & 0.9 & 2.6 & 2.3 \\
Minor PUFA & 0.5 & 1.6 & 1.2 \\
Total SFA & 32.3 & 29.3 & 32.3 \\
Total MUFA & 28.1 & 27.4 & 28.8 \\
Total PUFA & 39.7 & 43.8 & 39.2 \\
\end{tabular}

Values are percentages of total fatty acids. NFD, normal fat diet; EPA, eicosapentaenoic acid; DHA, docosahexaenoic acid; SFA, saturated fatty acid; MUFA, monounsaturated fatty acid; PUFA, polyunsaturated fatty acid; ND, not detected.
The telemetric transmitter (TL11M2-C50-PXT, DSI; St. Paul, MN) was surgically implanted in the abdominal cavity of the HI rats $(n=6)$. Blood pressure measurements were made using a floating catheter $(0.7 \mathrm{~mm}$ internal diameter and packed at the tip with gel to prevent thrombus formation), which was inserted $10 \mathrm{~mm}$ retrograde directly in the abdominal aorta and which was maintained by a drop of surgical glue (not by a ligature) to allow for regular blood flow. A pair of subcutaneous electrodes were inserted and fixed beneath the skin at the basis of the right forelimb and the left hindlimb to record the electrocardiogram (ECG) in a derivation similar to lead II in humans. Blood pressure, ECG, and total rat motion were received individually through specific Physiotel receivers (RLA1020, DSI) located under each cage and continuously recorded on a 2100 Mo FAST SCSI hard disk before analysis by the specific Dataquest IV program (DSI). Blood pressure and heart rate were monitored for $5 \mathrm{wk}$ in unrestrained conditions at 10-min intervals continuously for 3 days each week, starting 1 wk after surgery. The digital signals of blood pressure were sampled for $10 \mathrm{~s}$ every $10 \mathrm{~min}$. This monitoring resulted in $>2,500$ measurements per parameter for each rat. The first treatment was carried out to separate the night recordings (corresponding to the rat activity period) from the day recordings (corresponding to the rat resting period). The stressful $(2 \mathrm{~h})$ periods of transition between night/day and day/night were removed. The pathological evolution of blood pressure was expressed as the individual linear regression over $5 \mathrm{wk}$. The heart rate was studied as the difference between the last week and the initial data. To study the ECG, we selected the period of least activity (identified as a zero activity), which was always at the same time during the day and night. The same person analyzed all ECG records. Because the length of the QT interval is rate dependent, the QT analysis was realized on the transformed parameter $\mathrm{QT}_{\mathrm{c}}$ according to the following formula of Bazett: $\left[\mathrm{QT}_{\mathrm{c}}=\mathrm{QT}\right.$ (in $\left.\left.\mathrm{ms}\right) / \sqrt{\mathrm{R}-\mathrm{R} \text { interval (in } \mathrm{s})}\right]$.

Biochemical investigations. At the end of the experiment, the rats were killed by bleeding under anesthesia $(50 \mathrm{mg} / \mathrm{kg}$ pentobarbital). The blood was collected for serum biochemistries after an 8-h fast. Triglycerides (TG) and cholesterol were determined by spectrophotometry according to the procedures described in kits (Sigma Diagnostics TriglyceridesInt and Sigma Diagnostics Cholesterol, Sigma, respectively). Insulinemia was determined by radioimmunology using the kit Insulin-CT 100 In Vitro test, whereas glycemia was just measured using an automat One Touch.

The heart, adrenals, and kidneys were withdrawn and rinsed with saline. The organs were weighed and stored at $-20^{\circ} \mathrm{C}$ in $\mathrm{CHCl}_{3}-\mathrm{MeOH}(2: 1)$ to determine their fatty acids profile or frozen at $-80^{\circ} \mathrm{C}$ for the assessment of catecholamine content. The catecholamines were extracted from heart and adrenals in a solution containing EDTA ( $1 \mathrm{~g} / \mathrm{l}), 70 \%$ $\mathrm{HClO}_{4}(35 \mathrm{ml} / \mathrm{l})$, and dihydroxybenzylamine $(0.5 \mathrm{mg} / \mathrm{l}$ for hearts and $10 \mathrm{mg} / \mathrm{l}$ for adrenals as the internal standard) and analyzed as previously described (10). After centrifugation (20 $\mathrm{min}, 1,300 \mathrm{~g}, 4^{\circ} \mathrm{C}$ ), the supernatants were collected on activated alumina in Tris-EDTA-glutathione buffer ( $\mathrm{pH} 8.6$ ), and the catecholamines were eluted with perchloric acid and analyzed by HPLC coupled to electrochemical detection (42). The lipids were extracted from the heart and kidneys in 2:1 chloroform-methanol (12). Phospholipids (PL) were separated from nonphosphorous lipids (NL) on silica acid cartridges (22), and the fatty acids were trans-methylated with $\mathrm{BF}_{3}$-methanol (34). Methyl esters were analyzed by gas chromatography on an Econo-Cap EC-WAX capillary column $(0.32 \times 30 \mathrm{~m}$, Alltech Associates $)$ coupled to a flame ionization detector using C17:0 as the internal standard. 
Table 2. Morphometric data collected in control and HI rats at the end of the experiment and results of two-way ANOVA

\begin{tabular}{|c|c|c|c|c|c|c|c|c|c|}
\hline & \multicolumn{3}{|c|}{ Control Rats } & \multicolumn{3}{|c|}{ HI Rats } & \multicolumn{3}{|c|}{ ANOVA ( $P$ Values) } \\
\hline Heart weight, mg & $943 \pm 28.9$ & $906 \pm 37.2$ & $956 \pm 52.1$ & $877 \pm 29.5$ & $873 \pm 31.1$ & $915 \pm 36.2$ & NS & $<0.05$ & NS \\
\hline Heart weight, $\%$ body & & & & & & & & & \\
\hline weight & $0.22 \pm 0.004$ & $0.21 \pm 0.007$ & $0.21 \pm 0.009$ & $0.19 \pm 0.005$ & $0.19 \pm 0.007$ & $0.18 \pm 0.004$ & NS & $<0.001$ & NS \\
\hline Left ventricular weight, $\mathrm{mg}$ & $467 \pm 34.8$ & $485 \pm 36.7$ & $489 \pm 19.1$ & $480 \pm 22.2$ & $468 \pm 13.3$ & $517 \pm 24.0$ & NS & NS & NS \\
\hline
\end{tabular}

Values are means $\pm \mathrm{SE} ; n=6$ control rats and 6 hyperinsulinemic (HI) rats. CI, cross-interaction; NS, not significant.

Statistical analysis. Morphological and biochemical data are expressed as means $\pm \mathrm{SE}$ and analyzed by two-way ANOVA with one or two fixed factors among diet (NFD, EPA, or DHA), pathology (control vs. HI), and day vs. night variability. When significantly different, the means were further compared by one- or two-factor Neuman-Keuls test (7). For the telemetry-derived blood pressure measurements, a linear regression was carried out to determine the mean blood pressure progression per day (or per night) for each rat. A two-way multivariate ANOVA was then carried out on the 1,080 values per rat per parameter per period to take into account all the pressure parameters in each rat and to compare the individual blood pressure progression. The blood pressure data obtained by tail cuff were submitted to twoway ANOVA using diet and pathology as fixed factors. The heart rate was recorded by telemetry, and the data were subjected to linear regression of the evolution of cardiac frequency. Unfortunately, the individual variance due to environmental factors was so large that it masked any other changes that may have been induced by the pathology under investigation. This prevented the statistical analysis of these parameters. For this reason, all heart rate data were pooled to obtain an average value for the day and an average value for the night for each rat. Differences in these values among the groups were tested by ANOVA. The data collected for ECG were submitted to the same analysis.

\section{RESULTS}

Morphometric data. The morphometric data are shown in Table 2 . The evolution of the body weight of the rats was not affected by the dietary PUFA intake. At the end of the experiment, the body weight gain was greater in the $\mathrm{HI}$ rats than in the control rats, but this difference was not affected by PUFA intake. The insu- lin resistance induced by the fructose-rich diet elicited a slight reduction in heart weight (e.g., 5\%). This difference was found only for the whole heart and was not significantly different in the left ventricle or in the other parts of the heart (data not shown). Fructose intake also induced a significant renal hypertrophy. EPA or DHA intake did not affect these HI-induced morphometric changes. Similarly, the weights of the heart and kidneys were not affected by dietary DHA or EPA intake.

Biochemical data. Table 3 summarizes the effect of fructose and/or PUFA supplementation on several biochemical parameters. Compared with the control rats, the non-insulin-dependent rats exhibited HI associated with normoglycemia. These parameters were not influenced by dietary PUFAs, as in control rats. The insulin resistance induced a significant increase in plasma TGs, but no alteration in total plasma cholesterol. In both HI and control rats, the n-3 PUFA intake had no effect on TGs. Conversely, both EPA and DHA significantly reduced plasma total cholesterol in HI and control rats.

Neither the dietary PUFA intake nor the fructoseinduced diabetes affected epinephrine, norepinephrine, and dopamine content of the adrenal gland (data not shown). In the heart, only norepinephrine could be detected. Epinephrine and dopamine content were below the detection limits. The amount of cardiac norepinephrine was significantly higher $(\sim 20 \%$ increase in $\mathrm{ng} / \mathrm{g}$ ) in HI rats irrespective of the diet. This increase could not only be attributed to cardiac hypotrophy. In

Table 3. Biochemical data collected from the heart and plasma of control and HI rats at the end of the experiment and results of two-way ANOVA

\begin{tabular}{|c|c|c|c|c|c|c|c|c|c|}
\hline & \multicolumn{3}{|c|}{ Control Rats } & \multicolumn{3}{|c|}{ HI Rats } & \multicolumn{3}{|c|}{ ANOVA ( $P$ Values) } \\
\hline & NFD & EPA & DHA & NFD & EPA & DHA & $\begin{array}{l}\text { Diet } \\
\text { effect }\end{array}$ & $\begin{array}{c}\text { HI } \\
\text { effect }\end{array}$ & CI \\
\hline Cardiac NE, ng/heart & $695 \pm 42.1$ & $581 \pm 58.0$ & $577 \pm 61.8$ & $799 \pm 47.5$ & $696 \pm 37.5$ & $801 \pm 68.3$ & NS & $<0.001$ & $\overline{\mathrm{NS}}$ \\
\hline Cardiac NE, ng/g & $693 \pm 49.1$ & $603 \pm 58.1$ & $605 \pm 53.1$ & $850 \pm 77.4$ & $742 \pm 34.8$ & $865 \pm 58.9$ & NS & $<0.001$ & NS \\
\hline $\mathrm{TG}, \mathrm{g} / \mathrm{l}$ & $0.61 \pm 0.072$ & $0.41 \pm 0.021$ & $0.58 \pm 0.064$ & $0.84 \pm 0.144$ & $0.79 \pm 0.118$ & $0.78 \pm 0.116$ & NS & $<0.01$ & NS \\
\hline Total cholesterol, mg/l & $56.5 \pm 3.31$ & $41.2 \pm 5.23$ & $38.3 \pm 2.37$ & $53.0 \pm 2.24$ & $37.9 \pm 1.52$ & $33.6 \pm 1.88$ & $<0.001$ & NS & NS \\
\hline Insulinemia, $\mu \mathrm{U} / \mathrm{ml}$ & $278 \pm 32.2$ & $259 \pm 41.8$ & $350 \pm 47.3$ & $556 \pm 45.7$ & $568 \pm 44.6$ & $631 \pm 64.9$ & NS & $<0.001$ & NS \\
\hline Glycemia, mg/dl & $131 \pm 12.1$ & $121 \pm 5.1$ & $114 \pm 5.4$ & $114 \pm 4.6$ & $135 \pm 7.6$ & $123 \pm 7.9$ & NS & NS & NS \\
\hline
\end{tabular}

Values are means $\pm \mathrm{SE} ; n=6$ control rats and $6 \mathrm{HI}$ rats. NE, norepinephrine; TG, triglycerides. 
Table 4. PUFA composition of the total lipid fraction in the plasma of control and HI rats at the end of the experiment and results of two-way ANOVA

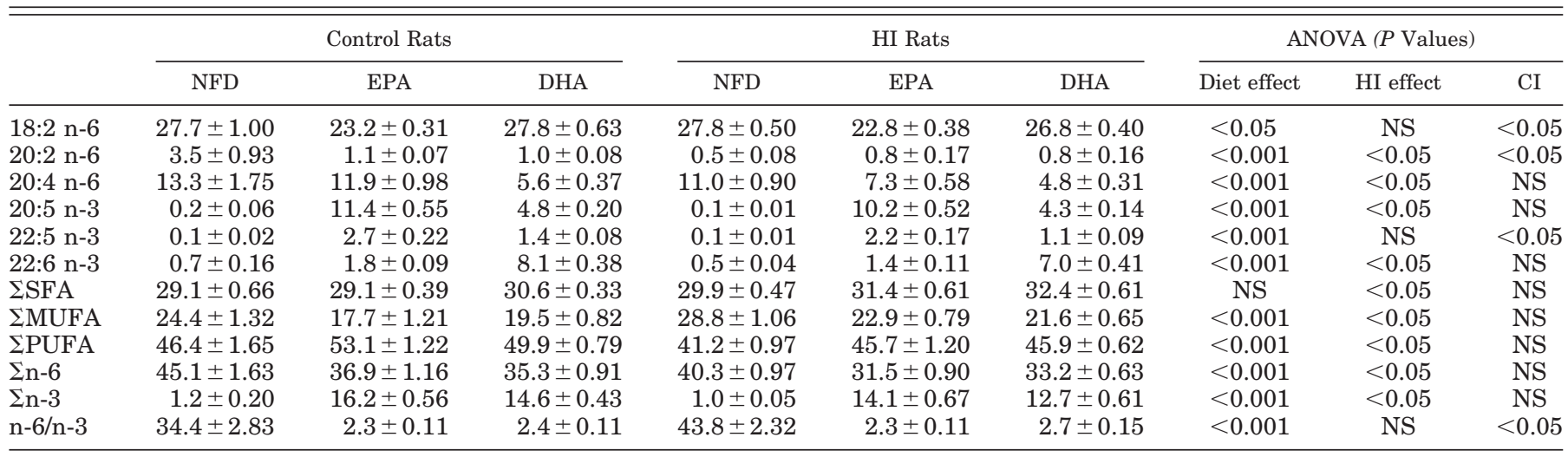

Values are means $\pm \mathrm{SE} ; n=6$ control rats and $6 \mathrm{HI}$ rats.

the control groups, the cardiac norepinephrine content was slightly lower in EPA- and DHA-fed rats, although this did not achieve statistical significance. This tendency for difference was not apparent in the HI rats.

Fatty acid composition. The fatty acid composition of the total lipid fraction of plasma is presented in Table 4. The diet significantly affected the plasma PUFAs mainly by increasing circulating EPA in the EPA-fed rats and DHA in the DHA-fed rats. Interestingly, the development of insulin resistance itself was associated with large alterations of the fatty acid composition. This included a significant decrease in arachidonic acid, EPA, and DHA, which resulted in a general decrease in circulating PUFA irrespective of the diet (no significant cross-interaction for $\Sigma$ PUFAs, $\Sigma$ n-6 PUFAs, and $\Sigma$ n-3 PUFAs; Table 4). Interestingly, this decrease in PUFA content was balanced for the most part by a significant increase in total MUFAs and a slight modification in total SFAs.

The fatty acid composition of the cardiac PL fraction was also determined (Table 5). SFAs and MUFAs were only weakly affected by n-3 PUFA supplementation. Conversely, the diet strongly altered the PUFA content in heart PLs. Dietary DHA strongly increased the myocardial DHA content. However, dietary EPA induced only a small increase in EPA (always low in cardiac membranes) and a greater increase in its elongated metabolite docosapentenoic acid (22:5 n-3). Dietary EPA failed to significantly increase the content of DHA in the heart. In both groups, the increase in n-3 PUFA was balanced by a significant decrease in arachidonic acid, which was significantly more pronounced in the DHA-fed groups. The development of insulin resistance did not noticeably alter the cardiac PL fatty acid composition except for the DHA content, which was, irrespective of the diet, slightly higher in the HI group than in the corresponding control. These results explain the significant effects of both the fructose diet and PUFA intake and the absence of crossinteraction between these two factors.

Blood pressure. Blood pressure was followed continuously by telemetry over a 5-wk period in the three groups of HI rats. The increase in blood pressure increase, as recorded with this nonstress technique, was moderate in this model ( $\sim 10 \mathrm{mmHg}$ over $5 \mathrm{wk})$ compared with the usual tail-cuff technique. A multivariate ANOVA was carried out to take into account the linear regression of all of the blood pressure parame-

Table 5. PUFA composition of the cardiac PL fraction in control and HI rats at the end of the experiment and results of two-way ANOVA

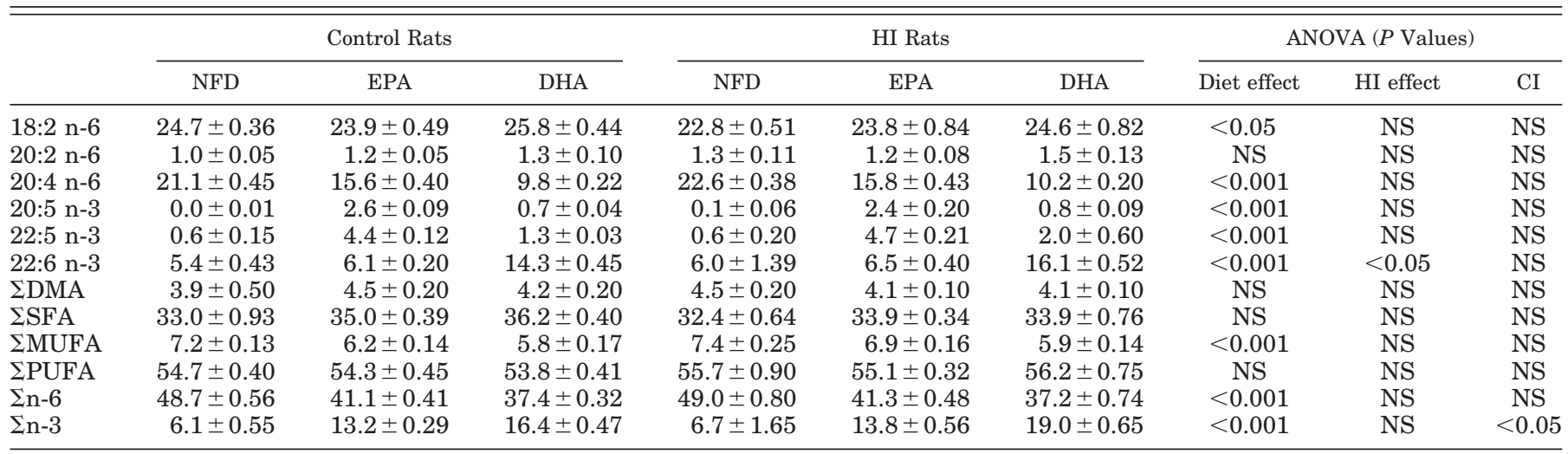

Values are means $\pm \mathrm{SE} ; n=6$ control rats and $6 \mathrm{HI}$ rats. PL, phospholipid. 
ters in each rat to evaluate the progression of blood pressure in each separate rat. The mean of the data obtained from all of the rats is shown in Fig. 1 for each group. This model of $\mathrm{HI}$ is characterized by an increase in blood pressure of $0.15-0.20 \mathrm{mmHg} /$ day in each rat. The increase was similar during the day (resting period) and the night (activity period). The dietary $n-3$ PUFA supplementation slowed the development of hypertension. The effect of EPA and DHA appeared to be more pronounced on diastolic pressure than on systolic pressure, although the statistical approach did not allow for a differentiation of these two parameters. The lack of significant cross-interaction between the two factors indicates that the effect of EPA and DHA on hypertension development was similar during day and night. This beneficial effect of dietary PUFAs on hypertension development was confirmed at week 5 by using a tail-cuff sphygmomanometer (Fig. 2). The values determined for blood pressure were obtained only during the day and were much more elevated than the values recorded by telemetry due to the stress associated with the tail-cuff technique. In all of the dietary groups, the control rats displayed a constant and low blood pressure of $\sim 116.3 \pm 3.33 \mathrm{mmHg}$ in the same conditions. At the same time, the blood pressure was significantly higher in the HI groups. However, this increase in blood pressure was significantly attenuated

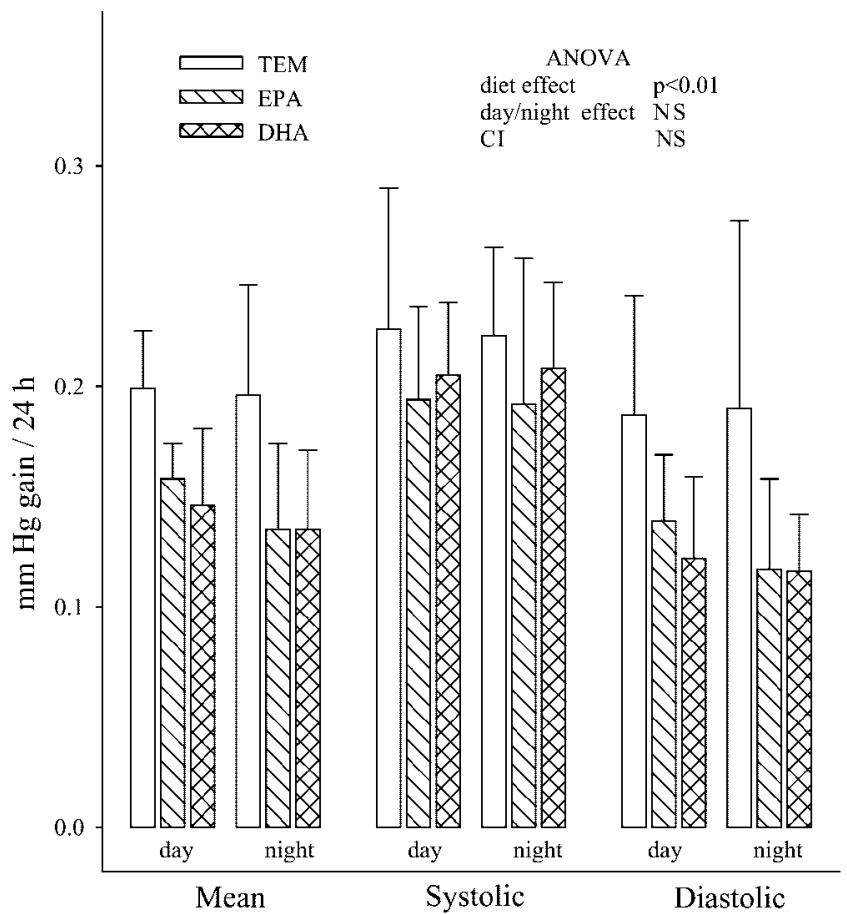

Fig. 1. Change in blood pressure ( $y$-axis; $\mathrm{mmHg}$ gain/24 h) as evaluated by linear regression of the individual data recorded by telemetry in the hyperinsulinemic (HI) rats during 5 wk $(n=6)$. Day and night data were examined separately because of the large changes in rat activity affecting blood pressure. TEM group, rats receiving a normal fat diet (NFD); EPA group, rats receiving the same fat diet supplemented with eicosapentaenoic acid; DHA group, rats receiving the same fat diet supplemented with docosahexaenoic acid; NS, not significant; CI, cross-interaction.

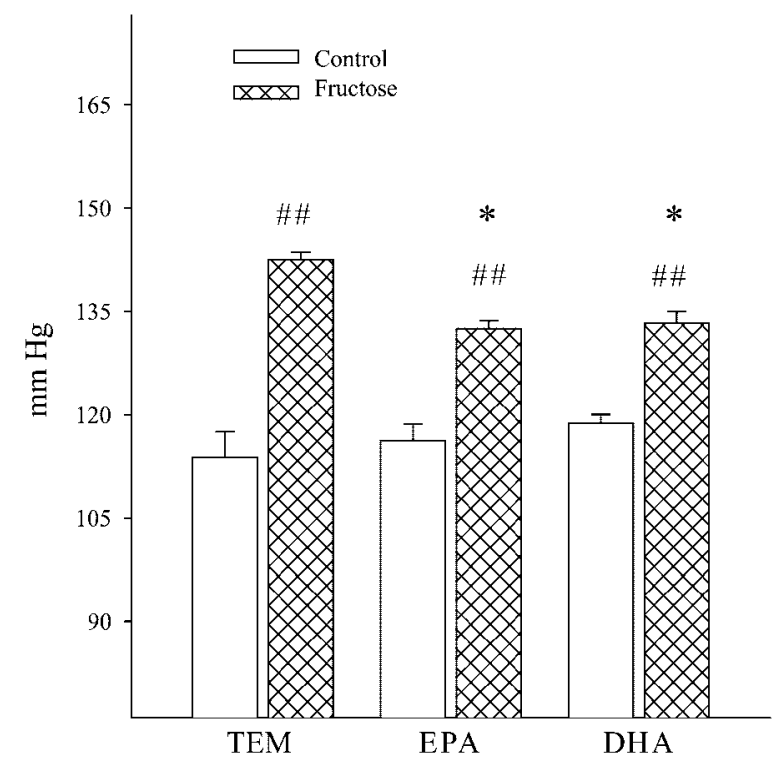

Fig. 2. Comparison of mean blood pressure ( $y$-axis; in $\mathrm{mmHg})$ in fructose-fed and control rats as determined by tail-cuff measurements after $5 \mathrm{wk}$ of experimental feeding. \#\#Significantly different from the corresponding control, $P<0.01$; * significantly different from NFD in the fructose-fed group (TEM), $P<0.05$.

in the EPA and DHA groups $(132.5 \pm 1.12$ and $133.3 \pm$ $1.67 \mathrm{mmHg}$, respectively) compared with the NFD group $(142.5 \pm 1.12 \mathrm{mmHg})$.

Heart rate. The heart rate was recorded throughout the study in the HI rats, and the individual linear regression of cardiac frequency in separate rats over time was determined. All of the rats displayed a very similar heart rate at the beginning of the study. The development of insulin resistance was associated with a slight increase in heart rate after 5 wk into the study. This was affected during daytime as well as nighttime (Fig. 3). The increase in heart rate was observed in the NFD-fed rats and the EPA-supplemented rats. However, no increase in heart rate could be observed in the DHA-supplemented rats. In this group of HI rats, the heart rate remained constant between weeks 0 and 5 during the activity period. A slight decrease could even be observed during the resting period. A moderate but significant decrease in overall activity in HI rats was detected (data not shown), which could account for the slight decrease in heart rate.

$E C G$. The ECG was continuously recorded in the HI rats during the whole experiment. The difference in heart rate between day and night was shown on the ECG by a shortened R-R interval during the active night period compared with the resting day period. The data collected from the ECG were analyzed by ANOVA, which confirmed that the heart rate was significantly lower in the DHA group than in the NFD and EPA groups in both the day and night periods (data not shown). None of the treatments applied in this study influenced the PR interval significantly (data not shown). However, because the length of the QT interval is rate dependent and our results indicated an effect of diet on heart rate, QT intervals were moni- 
A

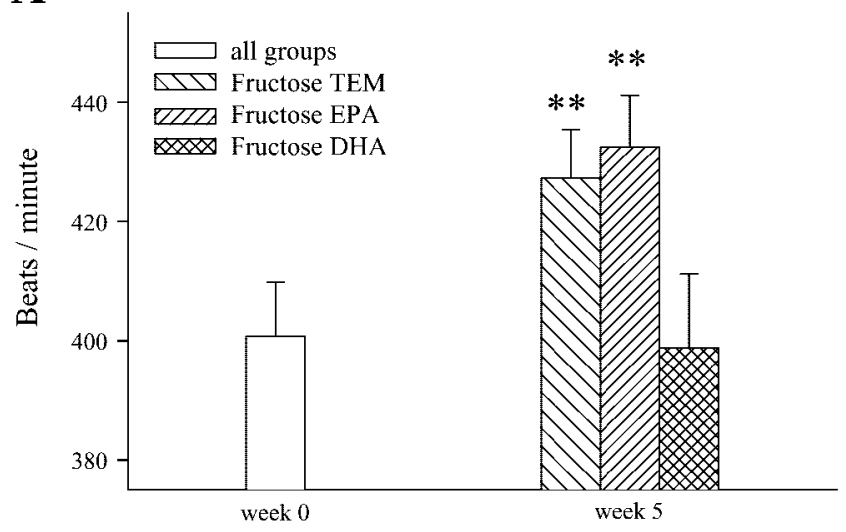

B

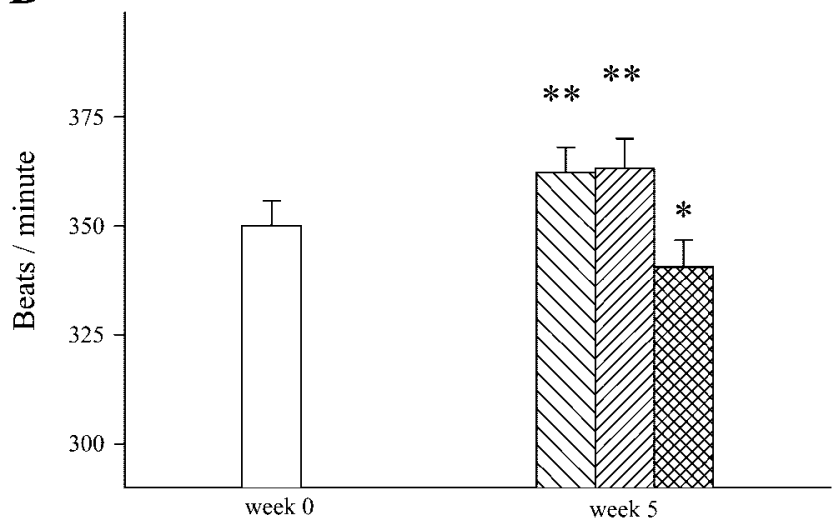

Fig. 3. Changes in heart rate ( $y$-axis; in beats/min) before and after the induction of $5 \mathrm{wk}$ of insulin resistance in the 3 dietary groups. Each bar represents the mean of 7 days. $A$ : day rest period. $B$ : night activity period. **Significantly different from control, $P<0.01$ * significantly different from control, $P<0.05$.

tored. QT analyses were made on the $\mathrm{QT}_{\mathrm{c}}$ because it takes into account the rate variations. The $\mathrm{QT}_{\mathrm{c}}$ was longer during the night than during the day (Fig. 4). There was a significant difference in the linear regression values for separate rats $(P<0.01)$ between the DHA group and the NFD and EPA groups, but there were no significant cross-interactions between diet and time (data not shown). However, after 5 wk of dietary supplementation, the $\mathrm{QT}_{\mathrm{c}}$ segment was significantly shorter in the DHA rats than in the two other groups during both day and night (Fig. 4).

\section{DISCUSSION}

This study was designed to assess the separate capacity of EPA or DHA to prevent the changes in heart function and blood pressure associated with $\mathrm{HI}$ in rats. Compared with the respective control animals, the fructose-fed rats exhibited HI, normoglycemia, hypertriglyceridemia, and moderate hypertension. These are characteristic alterations in this model (40). HI appears to play a central role in the development of fructose-induced hypertension in rats, and similar changes have been described in humans (19). At the end of the experiment, the fructose-fed rats displayed a greater body mass than the control rats despite an equivalent food intake, as also reported by others (37, 48). Neither in the HI nor in the control rats could EPA or DHA influence the plasma insulin concentration or body weight, as shown previously $(1,48)$. We observed a slight cardiac hypotrophy and a renal hypertrophy in the HI rats. This finding is at odds with other studies that have observed left ventricular hypertrophy in this model, but this may simply reflect their use of a much longer time periods than those used in the present study $(5,28)$. The glomerular changes observed in fructose-fed rats (5) were partly attributed to a reduced sodium excretion under the influence of increased plasma insulin (20). Again, EPA and DHA supplementation did not prevent heart or kidney mass changes.

Insulin resistance has been shown to be accompanied by an increase in plasma TGs (19). This was also observed in our study. Surprisingly, we did not observe any significant decrease in plasma TGs in the rats fed n-3 PUFAs, contrary to data reported in human clinical studies $(4,44,47)$. In humans, this effect is usually attributed to EPA $(13,49)$, and, in this study, plasma TGs were lower in the EPA group, although this difference was not significant. Our study may not have been long enough to allow the observation of a significant TG decrease. However, species specificity cannot be ruled out. The decrease in cholesterol levels due to $\mathrm{n}-3$ PUFAs that is observed in rats (as in this study) has not been duplicated in humans (13). The recommendation of fish oil for the diabetic population is, therefore, more often based on their effect on TGs than on a supposed effect on glucose metabolism (43).

Chronic feeding with diets high in fat or glucose was shown to increase blood pressure and enhance sympathetic activity in rats (23). This activation of sympathetic activity has been demonstrated during a HI, euglycemic clamp (33). In rats fed 66\% fructose, clonidine prevented hypertension but not the insulin resistance associated with fructose feeding. Reaven et al. (40) have suggested that the HI in this model may stimulate sympathetic nervous system activity that contributes to the hypertension but not to insulin resistance. Thus HI may enhance both blood pressure

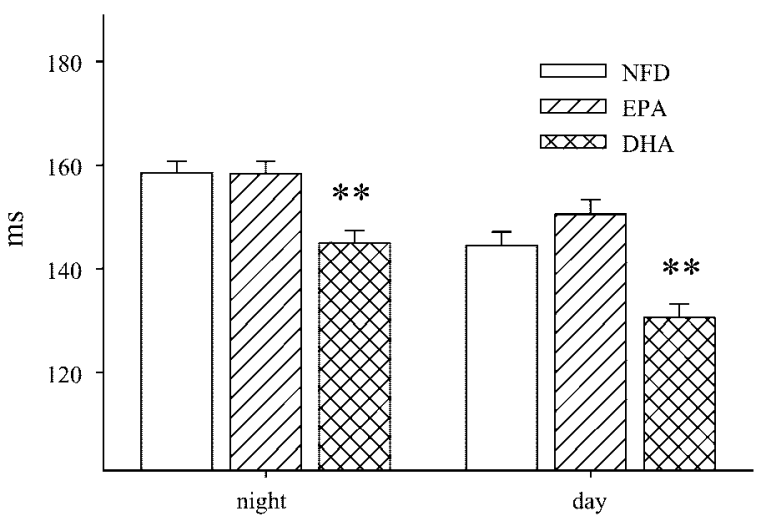

Fig. 4. ECG recording by telemetry in the HI rats of the 3 dietary groups. Mean values of the $\mathrm{QT}_{\mathrm{c}}$ segment ( $y$-axis; in $\mathrm{ms}$ ) during the last week of the experiment in the day resting period and night activity period are shown $(n=6)$. $* * P<0.01$. 
and sympathetic activity in the rat. Our results demonstrated an increased cardiac norepinephrine content in HI rats compared with controls, a result that may reflect the sympathetic hyperactivity associated with this model. Clearly, insulin is an important signal connecting dietary intake to sympathetic nervous system (25).

In fructose-fed rats, we observed a significant decrease in PUFA content, balanced by a MUFA and SFA increase. This decrease in PUFAs involved all of the functionally important C20 and C22 fatty acids, including arachidonic acid, EPA, and DHA. Dietary supplementation with EPA or DHA improved the n-3 PUFA status even in the fructose-fed rats, but worsened the arachidonic acid status associated with insulin resistance. These observations are in agreement with data reported in diabetic patients (2). Cardiac membranes are very sensitive to dietary-induced modifications of fatty acid composition (3). In this study, like in another (3), the dietary DHA intake induced a large increase in DHA incorporation in cardiac PLs in the control rats, balanced by a large arachidonic acid decrease. Conversely, although dietary EPA supplementation resulted in a slight increase in EPA and DPA in cardiac PLs and a slight reduction in arachidonic acid, it failed to significantly increase the cardiac DHA content. The effects of EPA and DHA dietary intake in HI rats were roughly similar to those of control rats, with a large improvement of DHA status by DHA intake but not by EPA intake. In the same model, both EPA and DHA were reported to increase 20:5 n-3, 22:5 n-3, and 22:6 $n-3$ and to decrease 20:4 n-6 in membranes (43). However, although cardiac membranes do accumulate both 20:4 n-6 and DHA, they incorporate very little of the EPA compared with other tissues (platelets, the liver, and kidneys) $(30,35)$. Moreover, dietary DHA (but not EPA) also slightly increased the cardiac linoleic acid content. DHA has been thought to stimulate the conversion of 18:2 n- 6 into $20: 4 n-6$ by decreasing $\Delta 6$ desaturase activity (21), which may explain the increased 18:2 n-6 and decreased 20:4 n-6 in the HI rats fed a DHA diet (38).

Although strongly affected by dietary PUFAs, insulin resistance did not significantly influence the cardiac membrane profile. This is unlike other organs such as the liver, kidneys, and adrenal glands (data not shown). Unlike Type 1 diabetic rats induced by streptozotocin treatment (insulin-dependent diabetes) (18, $24)$, HI rats in this study did not display increased 18:2 $\mathrm{n}-6$ in cardiac membranes. This suggests that the decreased $\Delta 6$-desaturase activity observed in insulin-dependent rats did not occur in insulin-resistant rats, or, alternatively, it may occur later. However, because HI does affect the PUFA status of cardiac membranes in this study, it should be noticed that supplementation with purified n-3 PUFA maintained the n-3 PUFA status in HI rats. This is in accordance with the specific requirement of the Type 1 diabetic heart for DHA (32). Our results suggest, therefore, that, although some fundamental differences do exist, Type 1 diabetes and insulin resistance may have some similarities in affect- ing n-3 PUFA incorporation into cardiac membrane. Insulin resistance is an additional risk factor for the $\mathrm{n}-3$ cardiac status, inducing a deficit in n-3 PUFA or a high $n-6$-to-n-3 ratio (45).

Fructose-induced hypertension in rats is a common model that has been used to investigate the relationship among HI, insulin resistance, and increased blood pressure. The results presented here show a $25-\mathrm{mmHg}$ increase of blood pressure as measured by tail cuff in the HI rats compared with control rats 5 wk after the beginning of the dietary intervention. This response is similar to that reported in similar experimental conditions using indirect measurements of blood pressure (48). The use of telemetry, which allows for a constant monitoring of the cardiovascular hemodynamic variables (blood pressure and heart rate) without manipulation of the rats, offers a higher sensitivity and accuracy for detecting blood pressure changes. The blood pressure values recorded by telemetry were significantly lower than those recorded by tail cuff. However, irrespective of the method for measuring blood pressure, the HI rats fed either EPA or DHA exhibited a lower blood pressure than did the HI rats fed a nonsupplemented fat diet. This effect of n-3 PUFAs was observed as the blood pressure rose over time, as the calculated mean gain per $24 \mathrm{~h}$, or after 5 wk. Interestingly, the prevention of the rise in blood pressure by n-3 PUFAs appears to be more pronounced for diastolic pressure than for systolic pressure. However, this is not statistically significant perhaps because of the large variability (means $\pm \mathrm{SE}$ ). The rat blood pressure is higher during the night, the period of activity, than during the day, when the rat is mainly sleeping. In the collected data, these two periods were examined separately and were always significantly different. However, neither the fructose diet nor the preventive effect by n-3 PUFAs could affect the differences between day and night. Moreover, all the dietary effects observed on blood pressure were similar between the EPA and DHA groups. These results clearly show that the effect of $n-3$ PUFAs in preventing the rise in blood pressure cannot be specifically attributed to either EPA or DHA but appears to be an effect of either PUFA.

The chronic increase of insulin is known to induce an increase in heart rate (33), which was also observed in the present study. This increase occurred in the HI rats fed both the NFD and the EPA-supplemented diet, with a larger amplitude during the activity period than during the resting period. On the contrary, the heart rate remained unchanged in the DHA group during the activity period, and we even observed a slight decrease during the resting period. The rise in heart rate during acute and chronic HI is often associated with an increase in cardiac output $(15,27)$. Supraphysiological levels of insulin increase cardiac contractility, as reflected by increased left ventricular $\mathrm{dP} / \mathrm{d} t(15)$. Unlike the blood pressure results, the effect of n-3 PUFA on heart rate was observed in the DHA-fed rats but not in the EPA-fed rats. This specific effect of DHA can be attributed to the presence of this fatty acid in cardiac membranes. With the use of isolated cardiac myocytes, 
it was shown that the presence of DHA but not EPA in the PLs decreases $\beta$-agonist-induced cAMP production (14). Moreover, in postischemic conditions, high membrane DHA levels strongly decrease the biochemical response to catecholamines (8), an effect that mimics the effects obtained with $\beta$-blockers. The involvement of DHA in the regulation of the $\beta$-adrenergic transduction mechanism may explain its effect on heart rate control in HI rats in vivo. In a previous study (42), involving a psychosocial stress in rats, our laboratory reported a reduction of cardiac contractility in DHAfed rats that could also be related to adrenergic regulation. The continuous analysis of ECG in HI rats revealed a significant increase of $R-R$ interval length in DHA-fed rats, which confirmed the decreased heart rate. A similar result was reported in sucrose-fed diabetic rats (16). Another result of the present study is the DHA-induced reduction of QT interval in HI rats. Again, this effect was observed with DHA but not with EPA. The diabetic heart is known to present a delayed afterdepolarization characterized by a longer QT interval. This early dysfunction is viewed as representative of the gradual change in the diabetic heart, i.e., cardiomyopathy with fibrosis and left ventricular hypertrophy (36). These characteristics are thought to be as an important component to explain the high risk of ventricular arrhythmias and sudden death observed in diabetic patients (6). The circadian variations of the QT interval and its heart rate dependency have been investigated, and it was shown recently that the daytime rate dependence of the QT interval is decreased with $\beta$-blocker therapy. This result suggests the influence of the sympathetic nervous system on the rate dependence of ventricular repolarization (11). Again, the relationship of DHA with the regulation of cardiac adrenergic system may account for the effect of DHA on the QT interval observed here in vivo in $\mathrm{HI}$ rats. Moreover, the QT interval is representative of the transmembrane ion channel activity that is dependent, in part, on modifications of cardiac plasma membrane composition. Previous results have shown that the incorporation of DHA into the plasma membrane can modulate $\mathrm{Ca}^{2+}$ channels (9) and $\mathrm{Na}^{+}$channels (26) to prevent arrhythmias (29).

In conclusion, the present study demonstrated that dietary EPA and DHA intake could not improve insulin resistance induced by high-fructose intake in rats. However, the circulatory (or vascular) and cardiac consequences of insulin resistance could be partly prevented by the fat intake. Both EPA and DHA were efficient in vivo in delaying and decreasing the rise in blood pressure, suggesting a positive effect in the prevention of hypertension associated with HI. Moreover, DHA, which readily incorporates in cardiac membranes, was able to prevent the increase in heart rate and QT interval length also associated with insulin resistance. The mechanism of this effect may be related to the regulation of cardiac adrenergic function by membrane DHA. Although this $\beta$-blocker-like activity was often suggested from in vitro studies, the present results provide indirect in vivo arguments. The results of this study demonstrate that purified n-3 PUFAs mimic the cardiovascular actions of fish oils and imply that DHA may be the principal active component conferring cardiovascular protection.

The authors are indebted to Dr. J.-C. Guilland and M. C. Riard and F. Duchêne (Centre Hospitalier Universitaire, Dijon, France) for contributions to catecholamine determinations. The authors are grateful to Dr. Valérie Arbin (Faculté de Pharmacie, Paris V, France) for the contribution to insulin determinations. The authors thank Cacao Barry for the generous gift of pure cocoa butter.

\section{REFERENCES}

1. Bexis SYK, Lungershausen MT, Mano PR, Howe JQ, Kong DL, Birkle D, Taylor A, and Head RJ. Dietary fish oil administration retards blood pressure development and influences vascular properties in the spontaneously hypertensive rat (SHR) but not in the stroke prone-spontaneously hypertensive rat (SHR-SP). Blood Press 3: 120-126, 1994.

2. Bohov P, Balaz V, Sebokova E, and Klimes I. The effect of hyperlipidemia on serum fatty acid composition in Type 2 diabetics. Ann NY Acad Sci 827: 561-567, 1997.

3. Charnock JS, McLennan PL, and Abeywardena MY. Dietary modulation of lipid metabolism and mechanical performance of the heart. Mol Cell Biochem 116: 19-25, 1992.

4. Connor WE. Fish oil in hypertriglyceridemia: safety and recommendations. Lipids 34, Suppl: S271, 1999.

5. Cosenzi A, Bernobich E, Plazzotta N, Seculin $\mathbf{P}$, and Bellini G. Bosentan reduces blood pressure and the targetorgan damage induced by a high-fructose diet in rats. $J$ Hypertens 17: 1843-1848, 1999 .

6. Coumel P, Johnson N, Extramiana F, Maison-Blanche $\mathbf{P}$, and Valensi P. [Electrocardiographic changes and rhythm problems in the diabetic.] Arch Mal Coeur Vaiss 93, Spec No 4: $59-66,2000$.

7. Dagnélie P. Théories et Méthodes Statistiques. Gembloux, Belgium: Presses Agronomiques de Gembloux Ed, 1975, vol. 2.

8. Delerive P, Oudot F, Ponsard B, Talpin S, Sergiel JP, Cordelet C, Athias P, and Grynberg A. Hypoxia-reoxygenation and polyunsaturated fatty acids modulate adrenergic functions in cultured cardiomyocytes. J Mol Cell Cardiol 31: 377386, 1999.

9. Durot I, Athias P, Oudot F, and Grynberg A. Influence of phospholipid long chain polyunsaturated fatty acid composition on neonatal rat cardiomyocyte function in physiological conditions and during glucose-free hypoxia-reoxygenation. Mol Cell Biochem 175: 253-262, 1997.

10. Eriksson BM and Persson BA. Determination of catecholamines in rat heart tissue and plasma samples by liquid chromatography with electrochemical detection. $J$ Chromatogr 228: 143-154, 1982.

11. Extramiana F, Tavernier R, Maison-Blanche $\mathbf{P}$, Neyroud $\mathbf{N}$, Jordaens L, Leenhardt A, and Coumel P. [Ventricular repolarization and Holter monitoring. Effect of sympathetic blockage on the QT/RR ratio.] Arch Mal Coeur Vaiss 93: 1277$1283,2000$.

12. Folch J, Lees M, and Sloane-Stanley GH. A simple method for isolation and purification of total lipids from animal tissues. J Biol Chem 226: 497-509, 1957.

13. Gruppo Italiano per lo Studio della Sopravvivenza nell'Infarto Miocardico. Dietary supplementation with n-3 polyunsaturated fatty acids and vitamin $\mathrm{E}$ after myocardial infarction: results of the GISSI-Prevenzione trial. Gruppo Italiano per lo Studio della Sopravvivenza nell'Infarto Miocardico. Lancet 354: 447-455, 1999.

14. Grynberg A, Fournier A, Sergiel JP, and Athias P. Effect of docosahexaenoic acid and eicosapentaenoic acid in the phospholipids of rat heart muscle cells on adrenoceptor responsiveness and mechanism. J Mol Cell Cardiol 27: 2507-2520, 1995.

15. Hall J, Brands M, Zappe D, and Alonso-Galicia M. Cardiovascular actions of insulin: are they important in long-term blood pressure regulation? Clin Exp Pharmacol Physiol 22: 689700, 1995. 
16. Hotta N, Koh N, Sakakibara F, Nakamura J, Hamada Y, Hara T, Mori K, Naruse K, Fukasawa H, Kakuta H, and Sakamoto N. Nerve function and blood flow in Otsuka LongEvans Tokushima Fatty rats with sucrose feeding: effect of an anticoagulant. Eur J Pharmacol 313: 201-209, 1996.

17. Howe PR. Dietary fats and hypertension. Focus on fish oil. Ann NY Acad Sci 827: 339-352, 1997.

18. Hu Q, Ishii E, and Nakagawa Y. Differential changes in relative levels of arachidonic acid in major phospholipids from rat tissues during the progression of diabetes. J Biochem (Tokyo) 115: 405-408, 1994.

19. Hwang IS, Ho H, Hoffman BB, and Reaven GM. Fructoseinduced insulin resistance and hypertension in rats. Hypertension 10: 512-516, 1987.

20. Hwang IS, Huang WC, Wu JN, Shian LR, and Reaven GM. Effect of fructose-induced hypertension on the renin-angiotensin-aldosterone system and atrial natriuretic factor. Am J Hypertens 2: 424-427, 1989 .

21. Iritani $\mathbf{N}$ and Fujikawa S. Competitive incorporation of dietary omega- 3 and omega- 6 polyunsaturated fatty acids into the tissue phospholipids in rats. J Nutr Sci Vitaminol (Tokyo) 28: 621-629, 1982.

22. Juaneda P and Rocquelin G. Rapid and convenient separation of phospholipids and non phosphorus lipids from rat heart using silica cartridges. Lipids 20: 40-41, 1985.

23. Kaufman L, Peterson M, and Smith S. Hypertension and sympathetic hyperactivity induced in rats by high-fat or glucose diets. Am J Physiol Endocrinol Metab 260: E95-E100, 1991.

24. Kuwahara T, Yanagishita T, Konno N, and Katagiri T. Changes in microsomal membrane phospholipids and fatty acids and in activities of membrane-bound enzyme in diabetic rat heart. Basic Res Cardiol 92: 214-222, 1997.

25. Landsberg L. Diet, obesity and hypertension: an hypothesis involving insulin, the sympathetic nervous system, and adaptative thermogenesis. Quarterly J Med 61: 1081-1090, 1986.

26. Leaf A, Kang JX, Xiao YF, Billman GE, and Voskuyl RA. The antiarrhythmic and anticonvulsant effects of dietary N-3 fatty acids. J Membr Biol 172: 1-11, 1999.

27. Lucchesi BR, Medina M, and Kniffen FJ. The positive inotropic action of insulin in the canine heart. Eur J Pharmacol 18: 107-115, 1972.

28. Lyer S, Katovich M, and Raizada M. Changes in angiotensin $\mathrm{AT}_{1}$ receptordensity during hypertension in fructose-fed rats. Adv Exp Med Biol 396: 49-58, 1996.

29. McLennan P, Abeywardena MY, and Charnock JS. Dietary fish oil prevents ventricular fibrillation following coronary artery occlusion and reperfusion. Am Heart J 116: 709-717, 1988.

30. McLennan P, Howe P, Abeywardena M, Muggli R, Raederstorff $D$, Mano M, Rayner T, and Head R. The cardiovascular protective role of docosahexaenoic acid. Eur J Pharmacol 300: 83-89, 1996.

31. McLennan PL, Abeywardena MY, and Charnock JS. The influence of age and dietary fat in an animal model of sudden cardiac death. Aust NZ J Med 19: 1-5, 1989.

32. McLennan PL and Raederstorff $\mathbf{D}$. Diabetes puts myocardial n-3 fatty acid status at risk in the absence of supplementation in the rat. Lipids 34, Suppl: S91-S92, 1999.
33. Meehan W, Buchanan T, and Hsueh W. Chronic insulin administration elevates blood pressure in rats. Hypertension 23: 1012-1017, 1994.

34. Morrisson WR and Smith LM. Preparation of fatty acid methyl esters and dimethyacetals from lipids with boron fluorid methanol. J Lipid Res 5: 600-608, 1964.

35. Murphy MG. Dietary fatty acids and membrane protein function. J Nutr Biochem 1: 68-77, 1990.

36. Nordin C, Gilat E, and Aronson R. Delayed afterdepolarizations and triggered activity in ventricular muscle from rats with streptozotocin-induced diabetes. Circ Res 57: 28-34, 1985.

37. Penicaud L, Berthault MF, Morin J, Dubar M, Ktorza A, and Ferre P. Rilmenidine normalizes fructose-induced insulin resistance and hypertension in rats. J Hypertens Suppl 16: S45-S49, 1998.

38. Raederstorff $\mathbf{D}$ and Moser U. Influence of an increased intake of linoleic acid on the incorporation of dietary (n-3) fatty acids in phospholipids and on prostanoid synthesis in rat tissues. Biochim Biophys Acta 1165: 194-200, 1992.

39. Rayner TE and Howe PR. Purified omega-3 fatty acids retard the development of proteinuria in salt-loaded hypertensive rats. $J$ Hypertens 13: 771-780, 1995.

40. Reaven GM. Abnormalities of carbohydrate and lipoprotein metabolism in patients with hypertension. Relationship to obesity. Ann Epidemiol 1: 305-311, 1991.

41. Rousseau D, Héliès-Toussaint $\mathbf{C}$, Raederstorff D, Moreau D, and Grynberg A. Dietary n-3 polyunsaturated fatty acids affect the development of renovascular hypertension in rats. Mol Cell Biochem 225: 109-119, 2001.

42. Rousseau D, Moreau D, Raederstorff D, Sergiel JP, Rupp H, Muggli R, and Grynberg A. Is a dietary n-3 fatty acid supplement able to influence the cardiac effect of the psychological stress? Mol Cell Biochem 178: 353-366, 1998.

43. Rustan AC, Nenseter M, and Drevon C. Omega-3 and omega-6 fatty acids in the insulin resistance syndrome. Ann NY Acad Sci 827: 310-326, 1997.

44. Sanders TA. Influence of omega 3 fatty acids on blood lipids. World Rev Nutr Diet 66: 358-366, 1991.

45. Simopoulos A. Omega-6/omega-3 fatty acid ratio and trans fatty acids in non-insulin dependent diabetes mellitus. Ann NY Acad Sci 827: 327-337, 1997.

46. Threshe JS, Podolin DA, Wei Y, Mazzeo RZ, and Pagliassotti MJ. Comparison of the effects of sucrose and fructose on insulin action and glucose tolerance. Am J Physiol Regul Integr Comp Physiol 279: R1334-R1340, 2000.

47. Turley E and Strain JJ. Fish oils, eicosanoid biosynthesis and cardiovascular disease: an overview. Int J Food Sci Nutr 44: 145-152, 1993.

48. Verma S, Bhanot S, and McNeill J. Antihypertensive effects of metformin in fructose-fed hyperinsulinemic hypertensive rats. J Pharmacol Exp Ther 271: 1334-1337, 1994.

49. Weber P. Triglyceride-lowering effect of n-3 long chain polyunsaturated fatty acid: eicosapentaenoic acid vs. docosahexaenoic acid. Lipids 34, Suppl: S269, 1999.

50. Wright D, Hansen R, Mondon C, and Reaven G. Sucroseinduced insulin resistance in the rat: modulation by exercise and diet. Am J Clin Nutr 38: 879-883, 1983. 